\title{
Effects of Longitudinal Vibration on Hardness of the Weldments
}

\section{S. P. TEWARI and Anand SHANKER}

Department of Mechanical Engineering, Institute of Technology, Banaras Hindu University, VARANASI-221005, India.

(Received on October 22, 1992; accepted in final form on September, 1993)

The paper pertains to the effects of longitudinal vibration, frequency and amplitude on hardness of the weldments prepared by metal arc welding under dynamic conditions. The frequency range was 0 to $400 \mathrm{~Hz}$ and amplitude range was 0 to $40 \mu \mathrm{m}$ respectively. Investigations show that the hardness of the weldments have increased when compared with the stationary welded test specimens. 0 to $400 \mathrm{~Hz}$ frequency range and 5 to $20 \mu \mathrm{m}$ amplitude range produce good results.

KEY WORDS: mild steel; weld; hardness; stationary; vibratory; frequency; amplitude.

\section{Introduction}

Hardness usually implies a resistance to deformation and for metals the property is a measure of their resistance of permanent or plastic deformation. To a person concerned with the mechanics of materials testing, hardness is most likely to mean the resistance to indentation and to the design engineer it often means an easily measured and specified quantity which indicates something about the strength and heat treatment of the

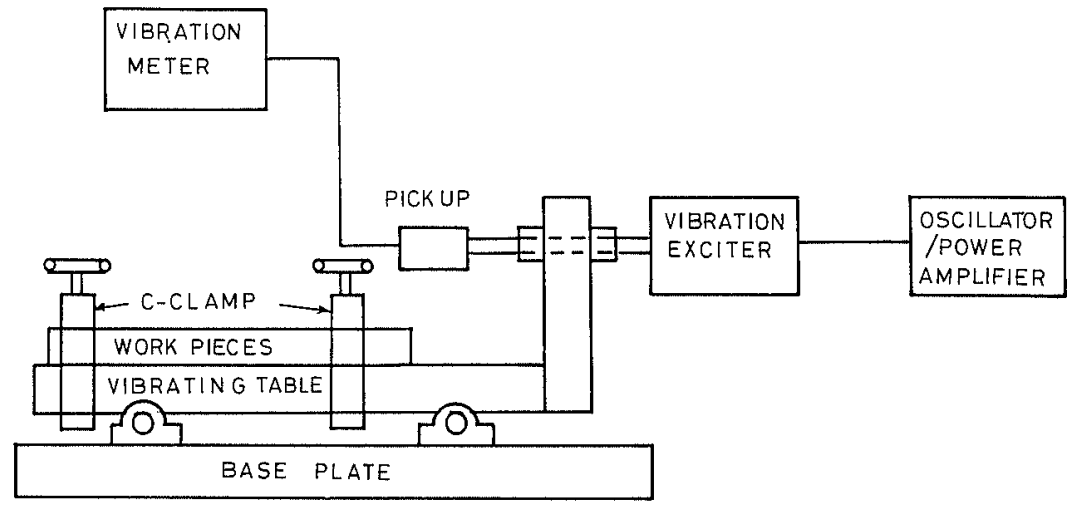

Fig. 1.

Experimental set up.

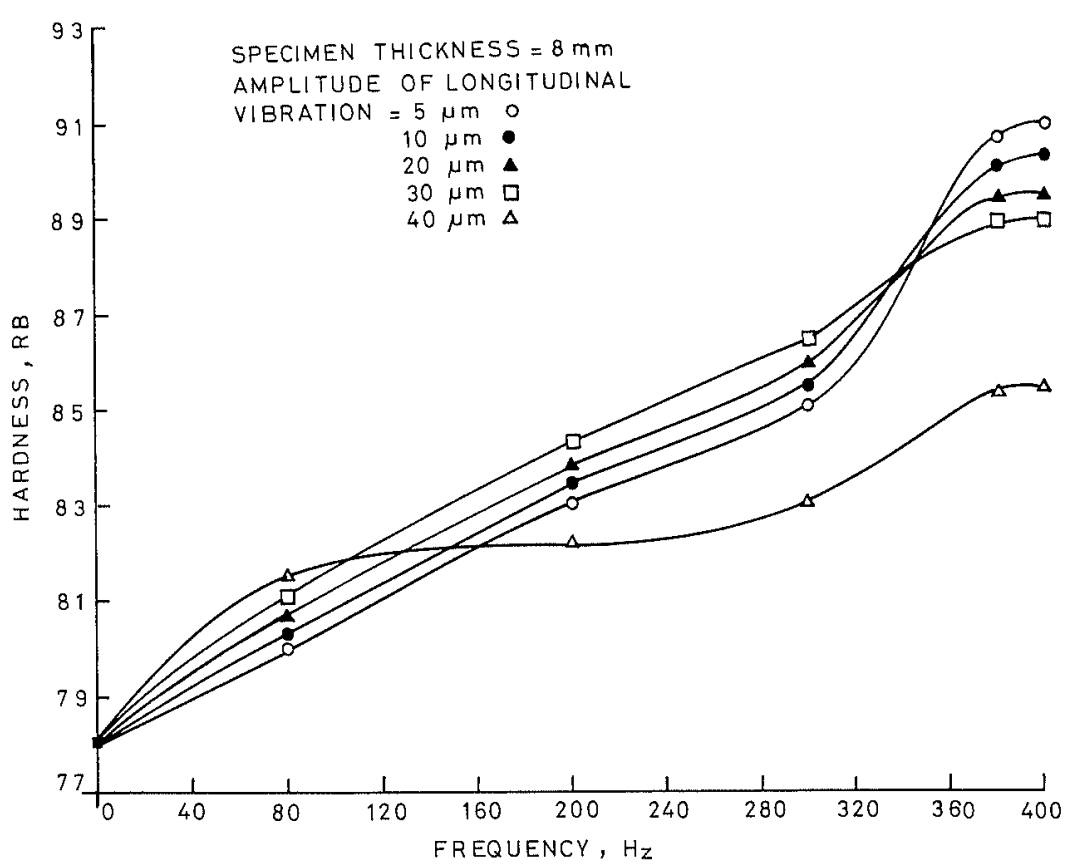

Fig. 2.

Effect of frequency on hardness at the centre of the weld zone in $x$ direction. 

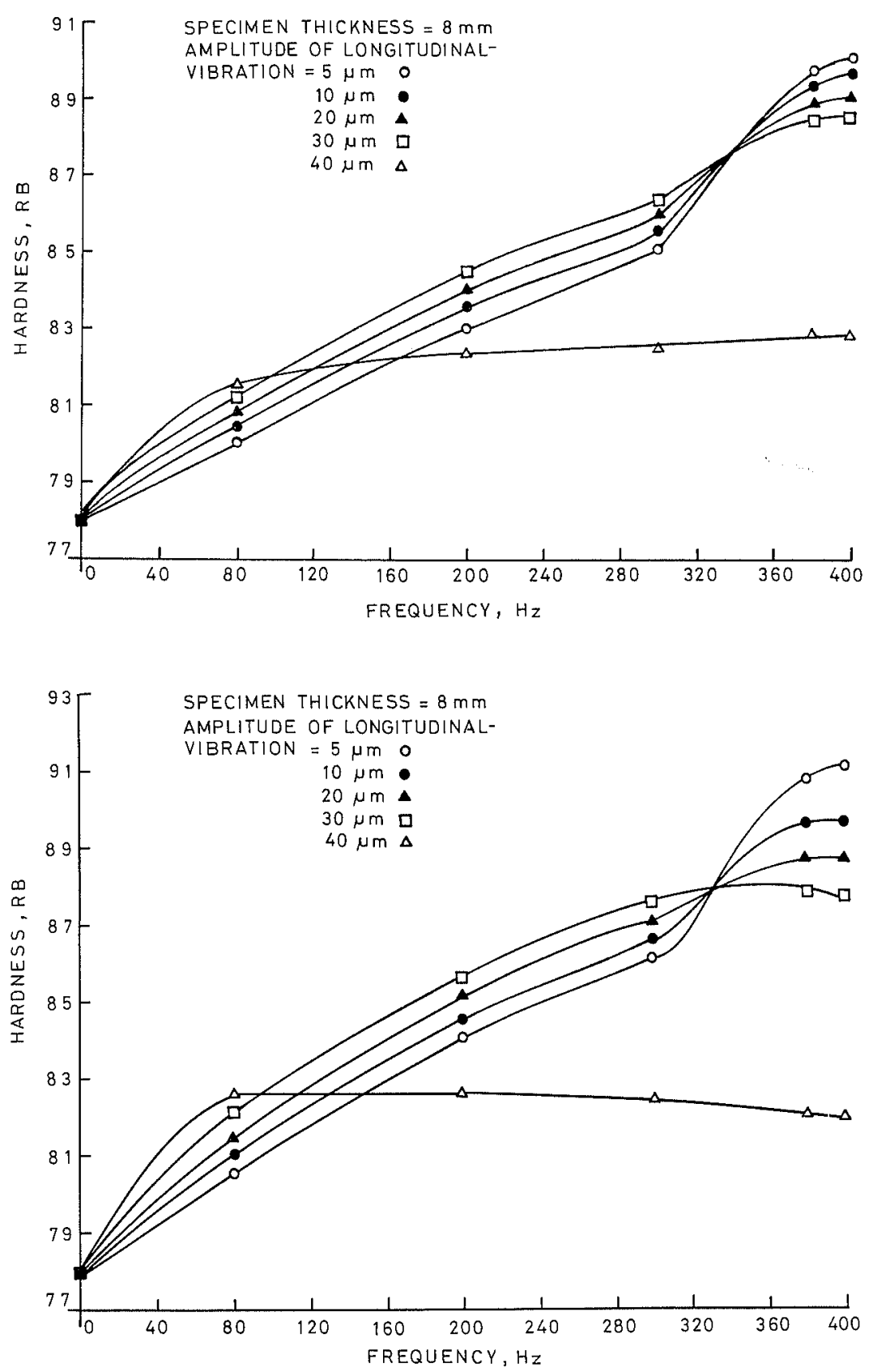

Fig. 3.

Effect of frequency on hardness at the centre of the weld zone in $y$ direction.
Fig. 4.

Effect of frequency on hardness at the centre of the weld zone in $z$ direction.

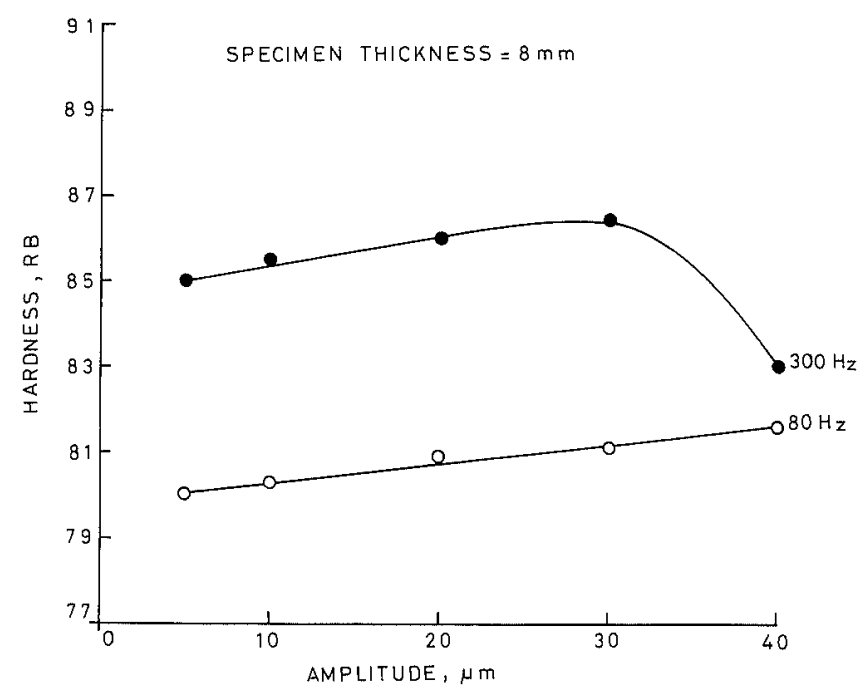

Fig. 5. Effect of amplitude on hardness at the centre of the weld zone. metal. There are three general types of hardness measurements depending on the manner in which the test is conducted, these are scratch hardness, indentation hardness and rebound or dynamic hardness. Dieter ${ }^{1)}$ (1987) observed that only indentation hardness is of major engineering interest for metals. The effects ${ }^{2,5,6)}$ (Shukla and Pandey 1976 and Shukla, Goel and Pandey 1980) on castings solidifying under vibration have pipe suppression, grain refinement, porosity reduction, metallographic refinement and improvement in the mechanical properties.

These effects depend on metal, method of introduction of energy into the solidification. Seal and Banerjee ${ }^{4)}$ (1984) studied grey cast iron solidification under vibration leads to varying micro structures and higher value of tensile strength. Kou and $\mathrm{Le}^{3)}$ (1985) observed that low frequency oscillations have shown improvements in structure and mechanical properties of aluminium welds. 

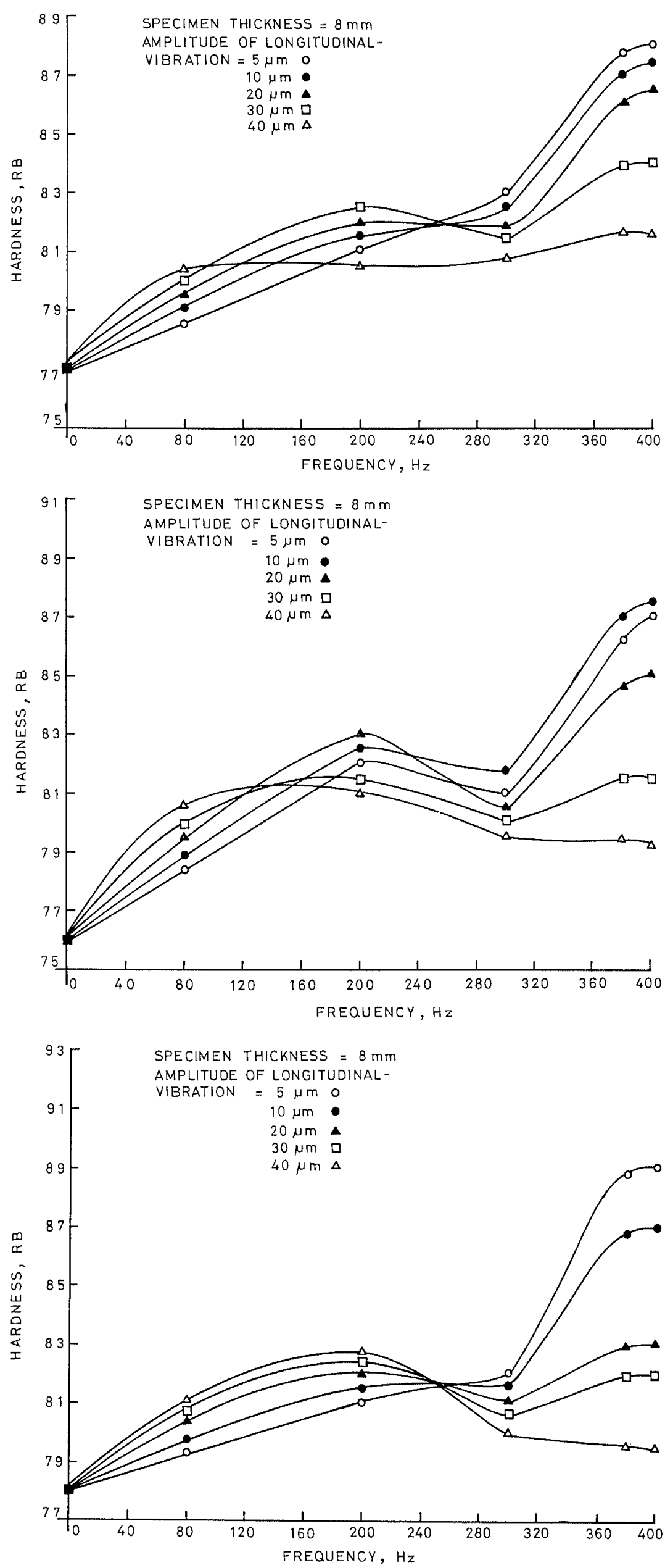

Fig. 6.

Effect of frequency on hardness at the extreme end of the weld zone in $x$ direction.

Fig. 7.

Effect of frequency on hardness at the extreme end of the weld zone in $y$ direction.
Fig. 8.

Effect of frequency on hardness at the extreme end of the weld zone in $z$ direction. 


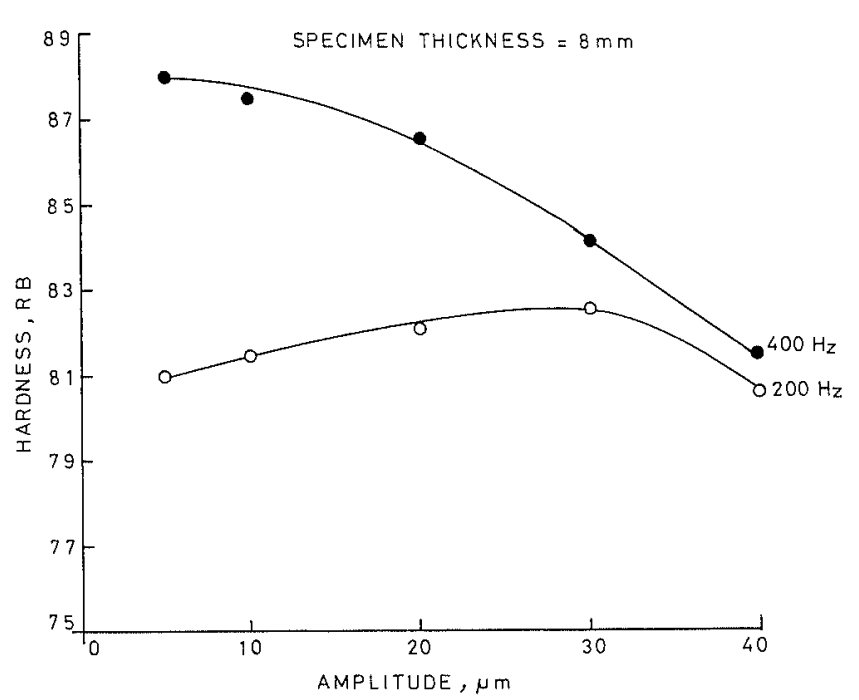

Fig. 9. Effect of amplitude on hardness at the extreme end of the weld zone.

Tewari ${ }^{7}$ observed that tensile strength and hardness increases in the frequency range of 40 to $80 \mathrm{~Hz}$.

The present paper deals with the effects of longitudinal vibration frequency and amplitude on hardness of the weldments in $x, y$ and $z$ planes at the centre of the welds and at the extreme ends of the welds.

\section{Experimental Programme}

Mild steel workpieces were clamped with C-clamps and angle iron pieces on the vibrating table (Fig. 1). These work pieces were welded under stationary and vibratory conditions. Vibrating table mounted on shafts supported on bearings was coupled to an electrodynamic vibrator. Three phase A.C. Transformer was used for welding. Welding was done with all position touch type mildsteel electrodes having rutile coating. Frequency and amplitude of longitudinal vibration were measured by oscillator/power amplifier and vibration meter respectively. Test specimens were made as per the standard specifications from stationary and dynamically welded workpieces. Hardness were measured on Rockwell hardness testing machine at centre point of the welds 2 , 7 and 4 for $x, y$ and $z$ directions respectively (Fig. 11). The hardness were also measured at the extreme ends of the welds i.e. at 1 and 3 for $x$ direction, 6 and 8 for $y$ direction and 2 and 5 for $z$ direction (Fig. 11).

\section{Results and Discussions}

Figures 2, 3 and $\mathbf{4}$ show the effects of frequency of vibration on hardness of the longitudinally vibrated test specimen along $x, y$ and $z$ planes of welds. These Figs. show that with increase in the frequency of vibration the hardness at the centre of the welds increases. Figure 5 illustrates that at $80 \mathrm{~Hz}$ frequency, increase in amplitude, increases hardness upto $40 \mu \mathrm{m}$ whereas at $300 \mathrm{~Hz}$ frequency, increase in amplitude increases hardness upto $30 \mu \mathrm{m}$ and then it has adverse effect on hardness. Figures 6, 7 and 8 illustrate that increase in frequency increases hardness at the extreme end of the welds along $x, y$ and $z$ planes of welds whereas Fig. 9 shows that at $200 \mathrm{~Hz}$
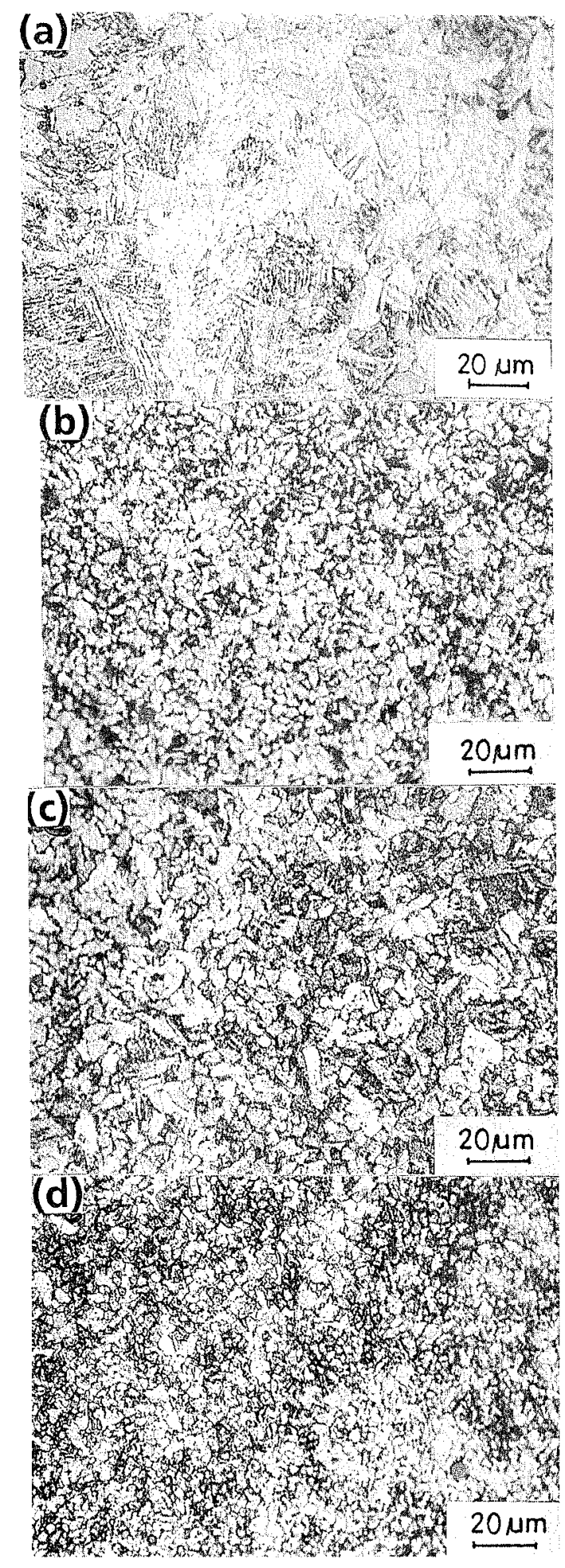

Fig. 10. (a) Micrograph of stationary welded specimen

(b) Micrograph of vibratory (longitudinal vibration) welded specimen (frequency-300 $\mathrm{Hz}$, amplilude $30 \mu \mathrm{m}$ ).

(c) Micrograph of vibratory (longitudinal vibration) welded specimen (frequency $-80 \mathrm{~Hz}$, amplitude $-40 \mu \mathrm{m})$.

(d) Micrograph of vibratory (longitudinal vibration) welded specimen (frequency-400 Hz, amplitude $-5 \mu \mathrm{m}$ )

Welding conditions: Metal-mild steel; electrode size $=4 \mathrm{~mm}$ dia., electrode code IS-E 316412 (AWS-E 6013), current $=135$ amps., voltage $=25$ volts 


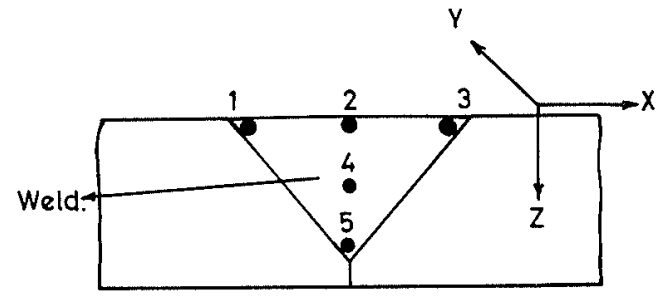

(a)

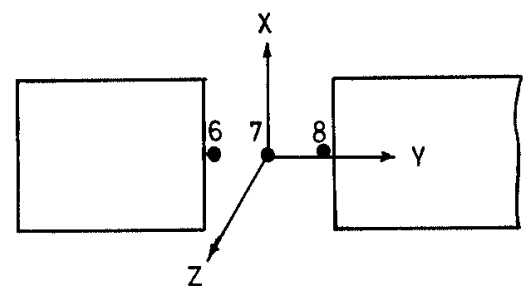

(b)

Fig. 11. Different points at which weld hardness measured.

frequency, amplitude increase upto $30 \mu \mathrm{m}$ has positive effect on hardness increase and then hardness decreases but for $400 \mathrm{~Hz}$ frequency amplitude increase decreases hardness values.

Figures 2 to 5 and Figs. 6 to 9 show that hardness at the centre and at the extreme ends of welds increases due to longitudinal vibration and this increase in hardness is almost uniform. It can be observed from all these figures that hardness of the specimens decreased when the amplitude of vibration was beyond $30 \mu \mathrm{m}$. This decrease in hardness may be attributed to the coarse and non uniform grain size distribution and improper fragmentation of grains nuclei at larger amplitude of vibration and frequency. This hardness increase is appreciable when compared with stationary welded specimens.

Figure 10(b, c, d) shows that the specimens welded under vibratory conditions have refinement in grain size when compard with stationary welded specimens which have coarser grains (Fig. 10a). Increase in hardness of the weldments may be attributed to grain refinement and uniform grain distribution gives almost uniform hardness.

\section{Conclusions}

Following conclusions may be derived on the basis of the experimental results.

(1) The welded specimens prepared under longitudinal vibration conditions of welding results in increased value of hardness at the centre of the weldments as well as at the extreme ends of the weldments.

(2) This increase in hardness in case of longitudinally vibrated test specimens is almost uniform at the centre of the weld and at the extreme ends of welds whereas for stationary welded test specimens hardness at the centre and extreme ends of welds is not uniform.

(3) Uniform, hardness and increase in hardness in case of specimens fabricated under vibratory conditions is because of grains are refined whereas in case of stationary welded specimens grains are coarser and non uniformly distributed.

\section{REFERENCES}

1) G. E. Dieter: Mechanical Metallurgy, McGraw-Hill, New York, (1987), 325.

2) D. B. Goel, D. P. Shukla and P. C. Pandey: Trans Indian Inst. of Met., 33, No. 3, (1980), 196.

3) S. Kou and Y. Le: Weld. J., (1985), 51.

4) A. K. Seal and M. K. Banerjee: Indian Foundry J., (1984), 15.

5) D. P. Shukla, D. B. Goel and P. C. Pandey: Metall. Trans., 11B, (1980), 166.

6) D. P. Shukla and P. C. Pandey: Indian Foundry J., (1976), 13.

7) S. P. Tewari: Indian Weld. J., (1986), 21. 